\title{
Escapable stress modulates retention of spatial learning in rats: Preliminary evidence for involvement of neurosteroids
}

\author{
DENIS J. HEALY and ROBERT C. DRUGAN \\ Brown University, Providence, Rhode Island
}

\begin{abstract}
The ability to escape stress has been shown to protect an organism from many of the deleterious effects of stress exposure. It has been suggested that this amelioration could be mediated by the release of an endogenous benzodiazepine-like substance in the brain demonstrated $2 \mathrm{~h}$ poststress. Since benzodiazepines possess amnestic as well as antianxiety actions, the possibility of memory alterations in coping subjects was evaluated. Animals were randomly assigned to three groups: escapable shock, yoked inescapable shock, and no shock. Immediately poststress, all subjects were trained in a circular water maze. Acquisition and retention data were obtained in a between-subjects design at three different retention intervals ( $2 \mathrm{~h}, 4 \mathrm{~h}$, and $24 \mathrm{~h}$ postshock). Results revealed no significant group differences in acquisition of the spatial learning task between groups. However, subjects in the escapable stress group had enhanced retention at $2 \mathrm{~h}$ postshock but were significantly impaired $24 \mathrm{~h}$ postshock relative to yoked-inescapable-shock and nonshock controls. Blockade of the synthesis of neuroactive GABA $_{\mathrm{A}}$ positive steroids by 4-MA, a 5-alpha reductase enzyme inhibitor, blocked this effect. Thus, neuroactive steroid metabolites may play a critical role in the escapablestress-induced retention deficit seen at $24 \mathrm{~h}$ poststress. These observations suggest that altered memory in the escapable-shock subjects may impart stress resiliency by reducing proactive interference of prior stress on subsequent learning and physiology.
\end{abstract}

The variety of pathologies caused by exposure to inescapable stress in both animal models and humans has been well documented. Deficits seen as a result of this exposure include interference with subsequent instrumental learning (Anisman \& Sklar, 1979; Maier \& Seligman, 1976; Seligman \& Maier, 1967), immunosuppression (Kusnecov \& Rabin, 1993; Laudenslager, Ryan, Drugan, Hyson, \& Maier, 1983; Seiber et al., 1992; Weiss, Sundar, \& Becker, 1989), opioid stress-induced analgesia (Drugan, Ader, \& Maier, 1985; Jackson, Maier, \& Coon, 1979), and gastric ulceration (Weiss, 1971). There are also many neurochemical changes in response to inescapable stress, including decreased dopamine levels in frontal cortex and mesocortical regions (Anisman \& Zacharko, 1990; Fadda et al., 1978; Fekete, Szentendrei, Kanyicska, \& Palkovits, 1981), norepinephrine depletion in whole

This research was conducted in partial fulfillment of the requirements for the master of science degree at Brown University for the first author (D.J.H.). The authors gratefully acknowledge the support for this research from PHS Grant MH45475 and the gift of 4-MA from L. Rhodes and G. Rasmusson of Merck, Sharp \& Dohme Research Laboratories. This study was presented at the Society for Neuroscience meeting in San Diego, California, November 1995. All behavioral procedures described were reviewed and approved by the Brown University Institutional Animal Care and Use Committee. The authors wish to thank Russell M. Church and J. Michael Walker for their valuable comments on the design of this study. Correspondence should be addressed to R. C. Drugan, Department of Psychology, University of New Hampshire, Conant Hall, 10 Library Way, Durham, NH 03824 . brain (Weiss, Stone, \& Harrell, 1970), cholinergic system hyperactivity (Anisman, Remington, \& Sklar, 1979), alterations in norepinephrine turnover (Tsuda \& Tanaka, 1985), decreased serotonin (5-HT) levels (Dunn, 1988; Petty, Kramer, \& Wilson, 1992; Sherman \& Petty, 1982), and decreased $\gamma$-aminobutyric acid (GABA) release in the hippocampus (Petty \& Sherman, 1981). However, exposure to equal amounts of escapable stress prevents many of the aforementioned deficits.

Many of the deleterious behavioral and neurochemical effects seen in uncontrollably stressed animals can be prevented by the administration of benzodiazepines (BDZs), which act to positively modulate GABAergic neurotransmission in central nervous system tissues (Braestrup, Schmiechen, Nielsen, \& Peterson, 1982; Lawrence, Gee, \& Yamamura, 1984; Paul, Syapin, Paugh, Moncada, \& Skolnick, 1982). Injections of BDZ tranquilizers, such as chlordiazepoxide or diazepam, prior to inescapablestress exposure attenuate both opioid stress-induced analgesia and instrumental learning deficits that would otherwise be observed (Drugan, Ryan, Minor, \& Maier, 1984; Sherman, Allers, Petty, \& Henn, 1979). In parallel, prestress administration of BDZs can antagonize ulceration, stress-induced increases in plasma corticosterone, as well as corticotropin releasing hormone-induced immunosuppression (File \& Pearce, 1981; Irwin, Hauger, \& Britton, 1993; Lefur, Guillox, Mitrani, Mizoule, \& Uzan, 1979) usually seen following inescapable stress.

In addition to pretreatment with BDZ compounds, many of the pathological effects of stress are attenuated 
by allowing the animals to make an active behavioral response to alter the onset, duration, intensity, or pattern of shock (Maier \& Seligman, 1976; Weiss, 1971; Weiss et al., 1970). The similarity between the protective effects of active escape behavior (i.e., "coping") and those of BDZ administration has led to the suggestion that active coping may afford protection from stress by the release of an endogenous BDZ-like substance (Drugan, McIntyre, Alpern, \& Maier, 1985). This suggestion has received recent support in that escapable stress is associated with a threefold increase of a substance in the brain that competes for BDZ binding sites (Drugan, Basile, Ha, \& Ferland, 1994).

Behavioral studies also provide support for this copinginduced release of an antianxiety compound. Escapably shocked animals show a reduced fear response when reexposed to contextual cues associated with the stressor (Desiderato \& Newman, 1971; Mineka, Cook, \& Miller, 1984), and they show no change in social interaction poststress (Short \& Maier, 1993). In addition, escapably shocked animals exhibit changes reminiscent of those that follow the administration of an antianxiety compound, including a protection from seizures induced by bicuculline (Drugan, McIntyre, et al., 1985) and picrotoxinin (Drugan et al., 1994), a GABA antagonist and a chloride channel antagonist, respectively.

If escapable shock is indeed associated with the release of a GABA-augmenting, antianxiety substance, memory interference might be expected, since many of these compounds also have amnestic properties (File \& Pellow, 1988; Izquierdo \& Medina, 1991; Katz \& Liebler, 1978; Lister, 1985; Lucki, Rickels, Giesecke, \& Geller, 1987; McNamara \& Skelton, 1992; McNaughton \& Morris, 1987; Thiebot, 1985; Venault et al., 1986). The protection afforded to escapable-shock subjects may be, at least in part, mediated by an impairment of the memory for the stress event. This memory deficit might be protective by reducing the proactive interference of the initial stress exposure on subsequent behavior. The present study was conducted to determine the impact of escapable stress on the acquisition and retention of animals in a spatial learning task. A place-learning task was chosen because it is highly sensitive to changes in hippocampal function, a brain area known to have changes in GABA action in response to stress (Foy, Foy, Levine, \& Thompson, 1990; Foy, Stanton, Levine, \& Thompson, 1987; Petty \& Sherman, 1981; Sherman et al., 1979), as well as $\mathrm{GABA}_{\mathrm{A}} / \mathrm{BDZ}$ receptor changes in the cortex and hippocampus of stress resilient subjects (Drugan et al., 1994; Drugan, Paul, \& Crawley, 1993). If escapable shock causes the release of an endogenous BDZ-like compound, then rats in the escapable-shock group should show poorer retention of the location of the submerged platform than should rats in the other groups.

\section{EXPERIMENT 1}

In Experiment 1, acquisition and retention data were obtained for escapable-shock, yoked-inescapable-shock, and nonshock groups. Acquisition functions were prepared by plotting the average latency to escape to the platform for each of the nine trial blocks ( 1 block $=2$ trials). Spatial memory was assessed using a betweensubjects design, with retention probes at three different temporal intervals: $2 \mathrm{~h}$ postshock, $4 \mathrm{~h}$ postshock, and 24 h postshock.

\section{Method}

Subjects. The subjects were 108 naive male Sprague-Dawley rats obtained from Charles River Laboratories. The animals weighed between 250 and $300 \mathrm{~g}$ at the initiation of the experiment. Prior to training, the animals were housed in polyethylene tub cages, 6 animals per cage, with food and water freely available. For the 4-h and the 24-h groups, the animals were individually housed in tub cages, with food and water ad lib during the posttraining interval. At all times, the animals were maintained on a 12:12-h light:dark schedule, with lights on at 6:00 a.m. All procedures were conducted during the first $6 \mathrm{~h}$ of the light cycle.

Apparatus. The escape-yoke shock stress paradigm was employed. Escapable and inescapable shocks were administered in two Plexiglas wheel-turn boxes by fixed tail electrodes and modeled after those used by Weiss et al. (1970) and Maier, Drugan, and Grau (1982). For the escapable-shock group, a grooved Plexiglas wheel extended $1.5 \mathrm{~cm}$ into the box through a hole approximately $8 \mathrm{~cm}$ above the floor of the box. The subjects could terminate the shock by spinning the wheel a predetermined number of times. The number of wheel turns required to terminate the shock was initially set at two turns and was monitored and increased as needed to maintain a shock duration of at least $2 \mathrm{sec}$ per trial. Inescapable-shock animals were placed in an identical Plexiglas box that did not have a wheel installed. Each yoked animal was paired with an escape animal that received the same intensity, duration, and pattern of shock.

Spatial memory training was conducted in a circular pool $(122 \mathrm{~cm}$ in diameter) that was filled with water to a depth of $51 \mathrm{~cm}$. The inner walls of the pool were painted white, and the water was made opaque by the addition of approximately $200 \mathrm{ml}$ of white, nontoxic liquid tempera paint. Water temperature was maintained at approximately $23^{\circ} \mathrm{C}$. During training, the animals swam to a submerged platform (approximately $1 \mathrm{~cm}$ below the surface) constructed of PVC pipe and clear Plexiglas, with a diameter of $10 \mathrm{~cm}$ and a height of approximately $50 \mathrm{~cm}$. Lighting in the water-maze training room was arranged so that illumination of the pool was equivalent in all quadrants. Both acquisition data and retention probe data were collected manually by viewing the animal's progress from a television camera connected to a monitor that was out of the view of the swimming animal. Training and retention probe swim sequences were not videotaped. Latencies to escape and time spent in the critical quadrant were measured with a standard stopwatch.

Procedure. The animals in this experiment were randomly assigned to three groups ( $n \mathrm{~s}=12$ per group). The animals in both the escapable-shock and the inescapable-shock groups received 80 intermittent tailshocks, averaging one shock per minute. Shock intensity began at $1.0 \mathrm{~mA}$ during the first 35 trials, was increased to $1.5 \mathrm{~mA}$ for the next 25 trials, and was increased to $2.0 \mathrm{~mA}$ for the last 20 trials. For both groups, the shock began simultaneously and ended when the escapable-shock animal responded. If the escape subject did not respond within $15 \mathrm{sec}$, the shock was automatically terminated. Escape subjects rapidly learned the wheelturn task, so that, by Trial 10 , the duration of shock received in each trial was approximately $2 \mathrm{sec}$. Nonshock control animals were housed individually in a colony room, without access to food or water during the $80-\mathrm{min}$ stress procedure.

Immediately following the shock procedure, all animals were trained in the Morris water maze (Morris, 1981). Water-maze train- 
ing was modeled after that employed by Warren, Castro, Rudy, and Maier (1991). Training consisted of 18 trials presented in nine blocks of 2 trials each. During all training and testing procedures, the experimenter was blind to the animal group membership. To orient the animals to the task, training began with placement of the animal's front paws onto the platform followed by $10 \mathrm{sec}$ of standing on the platform. Immediately after the third placement, the training commenced with the first block of 2 trials. The animals were placed into the pool at a different cardinal direction for each trial. Latency to escape to the platform was measured for each trial. If an animal failed to escape within $60 \mathrm{sec}$, the animal was placed onto the platform and a latency of $60 \mathrm{sec}$ was recorded. All animals were allowed to remain on the platform for $10 \mathrm{sec}$ after escape or placement. After a block of trials had been completed, the animal was returned to an empty tub cage and placed under a heat lamp during a 5 -min interval between blocks. The platform was placed in the center of the southwest quadrant for all training. Acquisition training was conducted simultaneously for all 3 subjects in the triadic design. Training sessions lasted approximately $70 \mathrm{~min}$ and were begun immediately poststress. Because of this, animals in the $2-\mathrm{h}, 4-\mathrm{h}$, and $24-\mathrm{h}$ retention intervals were tested at approximately $50 \mathrm{~min}, 2 \mathrm{~h} 50 \mathrm{~min}$, and $22 \mathrm{~h} 50 \mathrm{~min}$ posttraining, respectively.

After training, the animals in both the 4 -h and $24-\mathrm{h}$ retention groups were given approximately $45 \mathrm{~min}$ under the heat lamp to dry before being housed individually, with food and water freely available in tub cages for the duration of the posttraining interval. The animals in the $2-h$ retention group were allowed the same drying time but were given a retention probe immediately following this period.

Retention probes were conducted at $2 \mathrm{~h}, 4 \mathrm{~h}$, and $24 \mathrm{~h}$ postshock. Retention probes were conducted by removing the platform and allowing the animal to swim freely in the pool for $60 \mathrm{sec}$. Amount of time spent in the quadrant previously occupied by the platform and number of crosses over the previous position of the platform were recorded for each animal.

\section{Results}

Spatial learning acquisition. Acquisition curves were obtained for each group by calculating average latencies to escape to the platform for each block of 2 trials. As shown in Figure 1, the animals in all groups successfully learned to locate the escape platform within the 18 training trials. A repeated measures analysis of variance (ANOVA) was performed on the acquisition data. The ANOVA revealed a significant main effect of block $[F(8,256)=26.95, p=.0001]$, with no significant effect of group and no significant group $\times$ block interaction $[F(2,32)=0.35, p=.70$, and $F(16,256)=$ $1.17, p=.29$, respectively].

Spatial learning retention. Figure 2 shows the time spent swimming in the critical quadrant, employing a between-subjects design for the animals in escapable-, inescapable-, and no-shock groups at the three different retention intervals. These results represent two independent replications at each of the three timepoints.

When tested at $2 \mathrm{~h}$ postshock, the animals in the escapable-shock group exhibited a facilitated retention for the spatial location of the previously present platform. This observation was supported by a one-way ANOVA of the time spent swimming in the critical quadrant with a significant effect of group $[F(2,32)=8.44$, $p=.0011]$. A subsequent Newman-Keuls post hoc analysis revealed a significant difference $(p<.01)$ be-

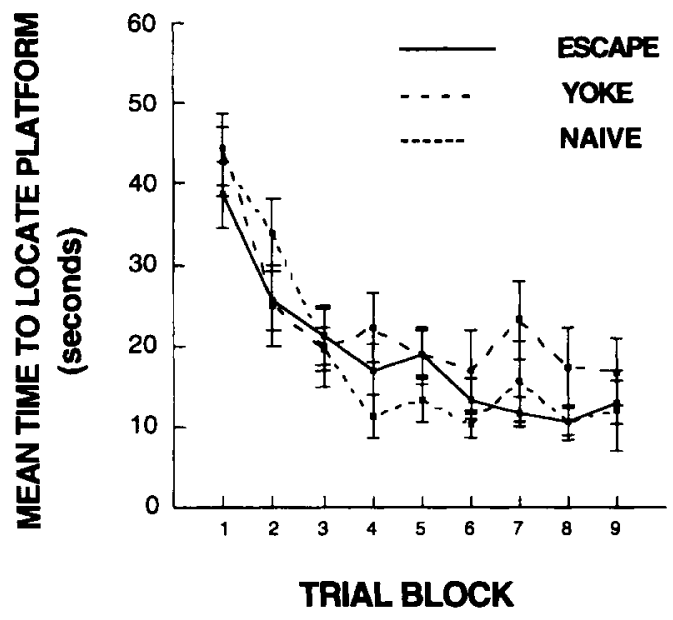

Figure 1. Mean latencies to locate submerged platform $( \pm S E M)$ across blocks of two trials for animals in escapableshock, inescapable-shock, and naive groups. Data displayed were obtained from animals at the 2 -h postshock retention time; however, the graph shown is representative of the acquisition data from the animals at the other retention intervals ( 4 and $24 \mathrm{~h}$ postshock).

tween escapable-shock animals and both inescapableshock and naive animals, which did not differ from one another. No significant differences in retention were observed at the 4-h-poststress probe trial $[F(2,26)=0.63$, $p=.54]$.

For the 24-h-poststress probe trial, the animals in the escapable-shock group showed an interference in retention relative to the inescapable-shock and naive groups. A one-way ANOVA revealed a significant effect of group $[F(2,33)=7.1359, p=.0027]$. A subsequent NewmanKeuls post hoc test showed that escapable-shock animals were significantly different from both inescapable-shock and no-shock animals ( $p \mathrm{~s}=.05$ and .01 , respectively), which did not differ from one another. The results demonstrating an escapable-shock-induced deficit observed $24 \mathrm{~h}$ postshock are consistent with the notion of the release of an endogenous BDZ-like compound with amnestic properties.

\section{EXPERIMENT 2}

Experiment 2 was conducted to evaluate the contribution of the GABA $/ B D Z$ receptor system on the memory deficit observed at the 24-h retention interval previously described. Since the classic BDZ antagonists have been shown to possess direct, intrinsic activity by enhancing spatial learning in the Morris water maze, we decided to avoid the use of these compounds (McNamara \& Skelton, 1993a). Other possible endogenous modulators of the $\mathrm{GABA}_{\mathrm{A}} / \mathrm{BDZ}$ receptor complex are the A-ring reduced metabolites of the steroid hormones progesterone and deoxycorticosterone.

Metabolites of the parent hormones progesterone and deoxycorticosterone, such as allopregnanolone and tetra- 


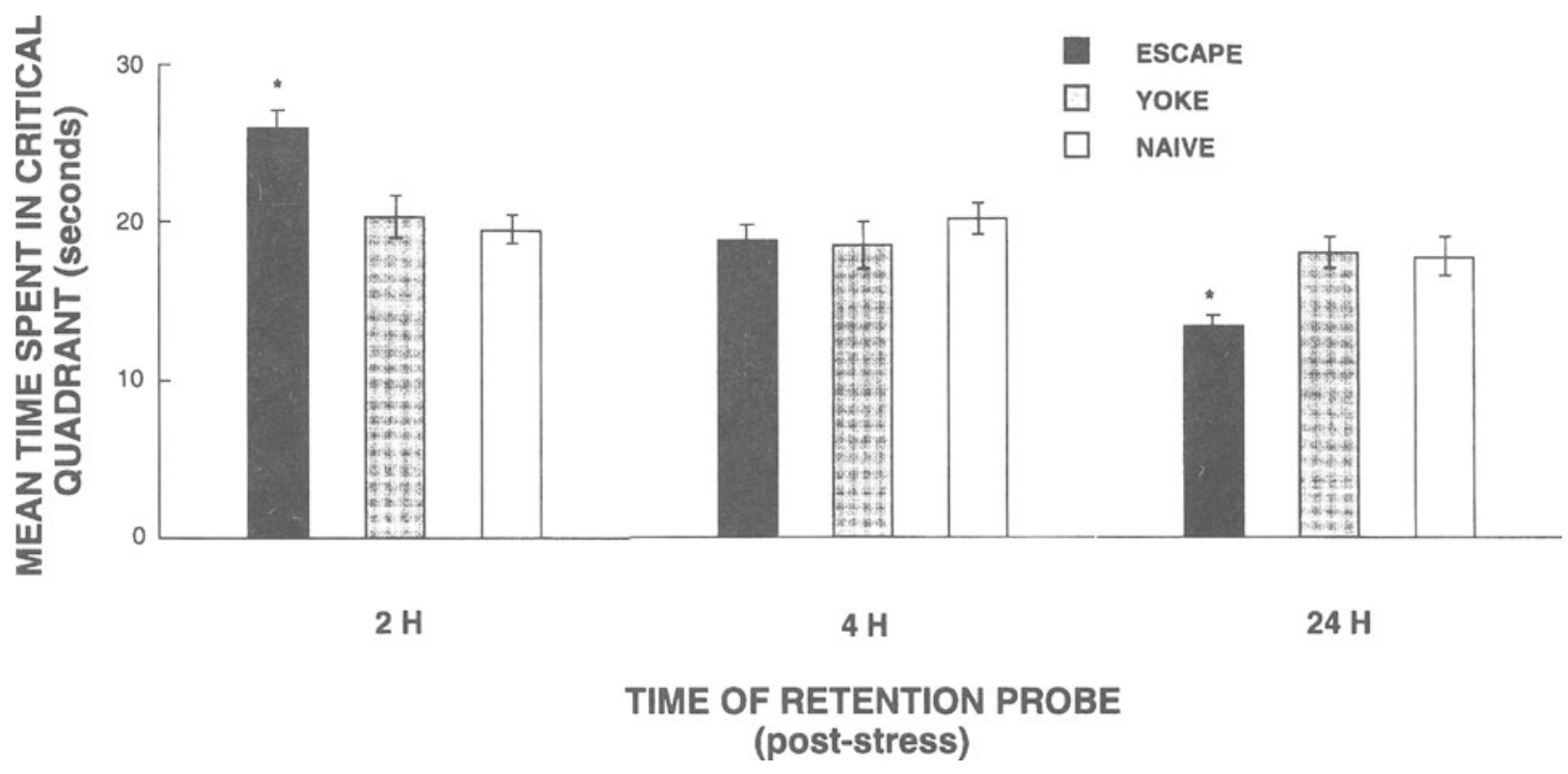

Figure 2. Mean time spent swimming in the critical quadrant ( $\pm S E M$ ) for animals in escapable-shock, inescapable-shock, and naive groups. Each bar represents mean time spent in the critical quadrant during a 60-sec retention probe given at one of three retention intervals $(2,4$, or $24 \mathrm{~h}$ postshock) using a between-subjects design. *Significantly different from both inescapable-shock and naive groups ( $p s<.01$, for 2 h postshock; $p s<.05$ and .01 , respectively, for 24 h postshock).

hydrodeoxycorticosterone, are positive modulators of the $\mathrm{GABA}_{\mathrm{A}} / \mathrm{BDZ}$ receptor complex. Many biochemical studies have demonstrated that these compounds, synthesized in brain tissues, potentiate GABA-induced chloride influx, allosterically modulate the activity of BDZ compounds, and modify $\left[{ }^{3} \mathrm{H}\right]$ muscimol and $\left[{ }^{35} \mathrm{~S}\right]$ TBPS binding in a manner reminiscent of $\mathrm{BDZ}$ or barbiturate administration (Costa, Auta, Guidotti, Korneyev, \& Romeo, 1994; Gee, Bolger, Brinton, Coirini, \& McEwen, 1988; Harrison, Majewska, Harrington, \& Barker, 1987; Majewska, 1992; Morrow, Pace, Purdy, \& Paul, 1989; Paul \& Purdy, 1992; Purdy, Morrow, Blinn, \& Paul, 1990). The behavioral manifestations of these compounds also closely resemble the effects of other positive modulators of the $\mathrm{GABA}_{\mathrm{A}} /$ $\mathrm{BDZ}$ complex. GABA positive neurosteroids have been shown to be anticonvulsant (Belelli, Bolger, \& Gee, 1989; Belelli, Lan, \& Gee, 1990; Kokate, Svensson, \& Rogawski, 1994), analgesic (Kavaliers \& Wiebe, 1987), and anxiolytic (Bitran, Hilvers, \& Kellogg, 1991; Bitran, Purdy, \& Kellogg, 1993; Crawley, Glowa, Majewska, \& Paul, 1986).

Stress-induced increases in $\mathrm{GABA}_{\mathrm{A}}$ receptor active neurosteroids following periods of acute stress have been demonstrated (Purdy, Morrow, Moore, \& Paul, 1991). The increase in these compounds is sufficient to modulate $\mathrm{GABA}_{\mathrm{A}}$ receptor function. It is hypothesized that these $\mathrm{GABA}_{\mathrm{A}}$ positive modulating neurosteroids may be responsible for the escapable-stress-induced memory impairment observed in the 24-h retention group in Experiment 1. Experiment 2 was conducted to evaluate the impact of a drug that inhibits the metabolic pathway responsible for production of $\mathrm{GABA}_{\mathrm{A}}$ positive neuro- steroids. N,N-diethyl-4-methyl-3-oxo-4-aza-5 alphaandrostane-17 beta-carboxamide (4-MA) is a potent inhibitor of the 5-alpha reductase enzyme responsible for catalyzing the reduction of parent steroid hormones into the bioactive $\mathrm{GABA}_{\mathrm{A}}$ positive modulators, allopregnanolone and THDOC (Toomey, Goode, Petrow, \& Neubauer, 1991). If the escapable-shock-induced deficit observed at the 24-h time point in Experiment 1 was the result of the action of an endogenous GABA active neurosteroid, we would expect to see a reversal of this deficit following the administration of the steroid synthesis inhibitor, 4-MA.

\section{Method}

Subjects. The subjects were 60 naive male Sprague-Dawley rats obtained from Charles River Laboratories. The animals weighed between 250 and $300 \mathrm{~g}$ at the initiation of the experiment. Housing, feeding, and light:dark conditions were identical to those in Experiment 1.

Apparatus. Stress and water-maze apparatus were identical to those in Experiment 1.

Procedure. The animals were randomly assigned to escapable-, inescapable-, or no-shock groups in either the drug or the vehicle condition. Immediately prior to the initiation of the stress procedure, the animals were injected subcutaneously with either $10-\mathrm{mg} /$ $\mathrm{kg} \mathrm{4-MA} \mathrm{or} \mathrm{an} \mathrm{equal} \mathrm{amount} \mathrm{of} \mathrm{vehicle} \mathrm{solution.} \mathrm{The} 10-\mathrm{mg} / \mathrm{kg}$ dosage was chosen on the basis of prior research demonstrating that this dose results in an initial inhibition of $80 \%$ at $15 \mathrm{~min}$ postinjection and a $60 \%$ inhibition of 5 -alpha reductase enzyme activity at $4 \mathrm{~h}$ postinjection (Toomey et al., 1991). After injection, stress procedure and training proceeded identically to that of Experiment 1 . Only the 24 -h retention test was employed in this experiment. Data collection was done manually by an experimenter blind to animal group membership. No training or retention swim sequences were videotaped. 


\section{Results}

Due to training difficulties in Experiment 2, a learning criterion was established to remove animals that were deemed bad learners from the analysis. If the average latency to locate the platform during Training Trials 2-6 was greater than the average latency for Trials $15-18$, the animal remained in the analysis. If the average latency of Trials 2-6 was less than the latency for Trials $15-18$, the animal was removed. This criterion resulted in the removal of 6 animals. Each group was equally affected by the implementation of the criterion, and statistical analysis of acquisition data was roughly equivalent both before and after criterion animals were removed.

Spatial learning acquisition. Acquisition curves were obtained as in Experiment 1. As shown in Figure 3, the animals in all groups successfully learned to locate the escape platform within the 18 training trials. A repeated measures ANOVA was performed on the acquisition data. The ANOVA revealed a significant main effect of block $[F(8,328)=52.82, p<.0001]$, with no significant effects of group $[F(2,41)=0.12, p=.883]$, drug $[F(1,41)=0.001, p=.949]$, group $\times$ block interaction $[F(16,328)=0.87, p=.609]$, or drug $\times$ block interaction $[F(8,328)=1.92, p=.057]$.

Spatial learning retention. Figure 4 shows the time spent swimming in the critical quadrant for the animals in the three different stress conditions in each of the two drug conditions. Note that the results of Experiment 1 were replicated. When injected with the vehicle, the rats in the escapable-shock condition spent less time in the training quadrant than did the rats in the yoked or naive conditions. The rats in the 4-MA drug conditions, however, showed a different pattern of results. The effects of escapable shock were prevented by 4-MA because there was no difference between the rats in the escapableshock and naive conditions. In addition, 4-MA-treated rats in the yoked condition spent less time in the training quadrant than did the rats in the naive condition. These results were confirmed with a two-way ANOVA of the time spent swimming in the critical quadrant, with a significant effect of group $[F(2,43)=4.4895, p=.0170]$, a significant effect of drug $[F(1,43)=4.3063, p=.0440]$, and a significant group $\times$ drug interaction $[F(2,43)=$ $4.6759, p=.0145]$. A subsequent Newman-Keuls post hoc test showed that the vehicle-escape group differed significantly from both the 4-MA-escape and the 4-MAnaive group ( $p s<.05$ and .01 , respectively) and that the 4-MA-yoke group differed from both the 4-MA-escape and the 4-MA-naive group ( $p \mathrm{~s}<.05$ ).

\section{DISCUSSION}

In both experiments, escapable- and inescapable-shock exposure had no effect on the acquisition of place learning when training occurred immediately poststress. This equivalence in acquisition among the groups was evident for all independent between-subjects design experiments testing the three retention intervals. An effect of escapable shock was found for the retention of place learning. Escapable-shock subjects given a retention probe trial at $2 \mathrm{~h}$ poststress showed a significant increase in the retention of the location of the platform. The animals in the inescapable-shock and naive groups were indistinguishable at the 2-h time point. At $4 \mathrm{~h}$ poststress, retention differences seemed to disappear, with no significant difference between groups. However, when the animals were
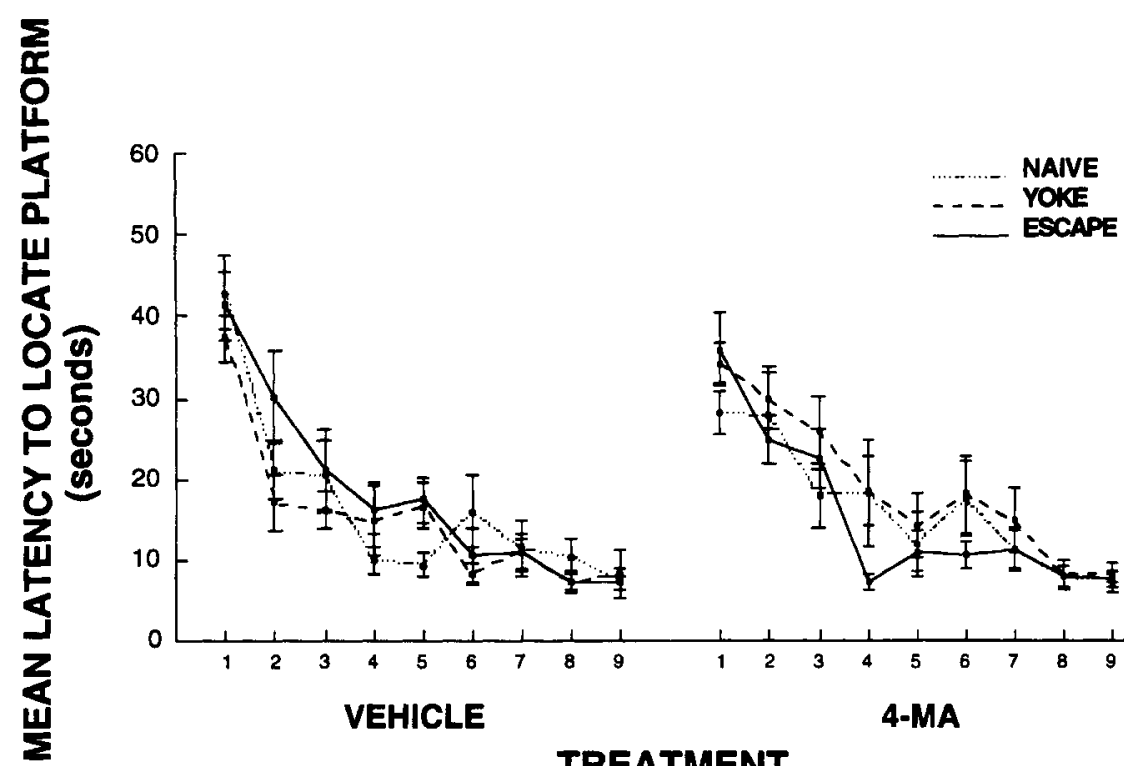

\footnotetext{
Figure 3. Mean latencies to locate submerged platform $( \pm S E M)$ across blocks of two trials for animals in escapable-shock, inescapable-shock, and naive groups. Data displayed are for both vehicle and 4-MA drug conditions.
} 


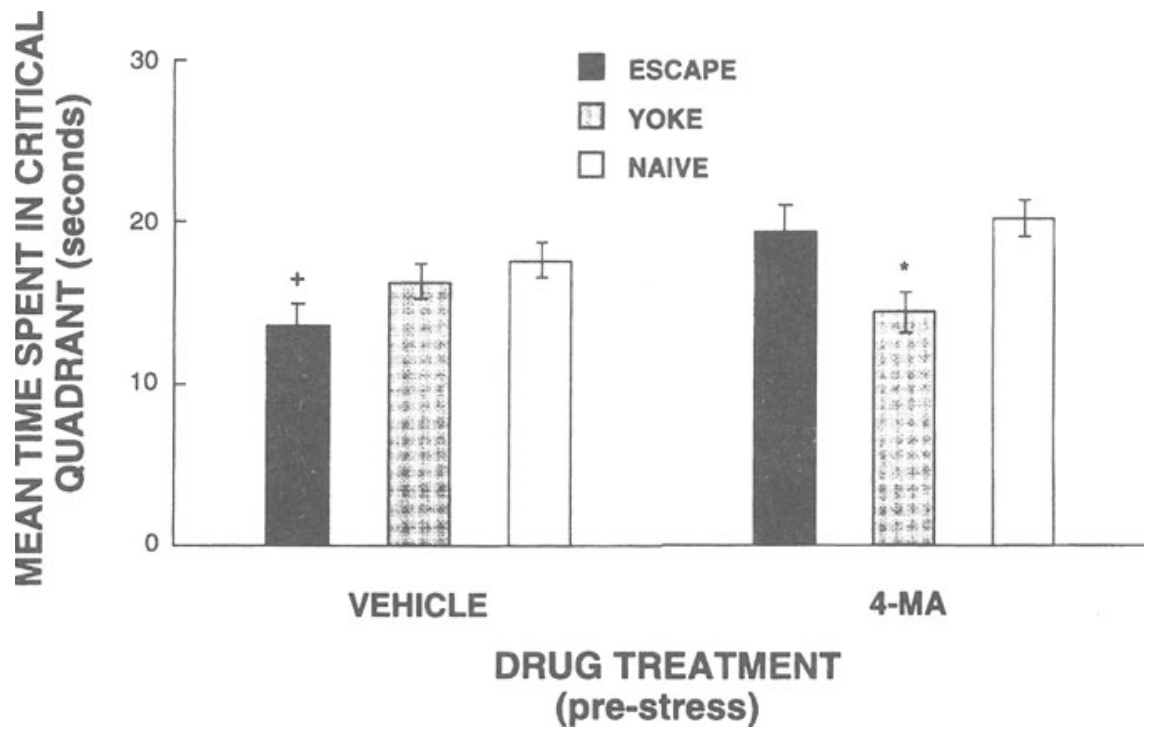

\begin{abstract}
Figure 4. Mean time spent swimming in the critical quadrant $( \pm S E M)$ for animals in escapable-shock, inescapable-shock, and naive groups. Data displayed are for both vehicle and 4-MA drug conditions. Each bar represents mean time spent swimming in the critical quadrant during a 60-sec retention probe given 24 h poststress. + + Significantly different from both 4-MA naive and 4-MA escape ( $p s<.01$ and .05 , respectively). *Significantly different from both 4-MA escape and 4-MA naive $(p s<.05)$.
\end{abstract}

given a retention probe at $24 \mathrm{~h}$ poststress, the escapableshock animals spent significantly less time in the critical quadrant, whereas the inescapable-shock and naive subjects were indistinguishable. The present results showing equivalent performance in acquisition and retention in both inescapable-shock and naive animals confirm the results of Warren et al. (1991). It appears, however, that the crucial factor determining the effect of stress on spatial memory, employing the current time course and watermaze training, is the psychological dimension of stress control.

The enhanced performance of the animals in the escapable-shock group at the 2-h retention probe seems paradoxical in light of the hypothesis of these experiments. If an endogenous BDZ is released in escapableshock animals between immediately and $2 \mathrm{~h}$ poststress, a memory impairment (retrograde amnesia) would be expected rather than a facilitation of retention (Izquierdo $\&$ Medina, 1991). It may be that the retention times for the escapable-shock animals at the 2-h time point may be the result of a facilitation of short-term memory and that retention deficits seen at the 24-h time point may reveal a long-term memory impairment. Thus, BDZ-like compounds may have a bidirectional effect on shortterm versus long-term memory. This possibility has been supported in the clinical literature (Hinrichs, Ghoneim, \& Mewaldt, 1984).

If an endogenous GABA positive modulator (e.g., GABA mimetic, BDZ, neurosteroid) is released in response to escapable stress, one would expect memory deficits similar to those that we have demonstrated in the escapable-shock group at the $24-\mathrm{h}$ retention interval. The impaired memory seen in these animals may provide an alternative explanation for the protection that escapably shocked animals are afforded against subsequent learning deficits and stress pathology. An organism that has an impaired memory for events closely related to a stressful situation may be protected from the proactive interference of marked emotional reactivation upon subsequent exposures to the same or similar events. That is, the effect of stress control may be prophylactic not only because it reduces fear/anxiety and its neurobiologic correlates but also because the "emotional" memory for the stressful event has been compromised.

The results of Experiment 2 provide further evidence for the involvement of the GABAergic system in the mediation of spatial learning and memory. The amnestic effects of escapable shock appear to be mediated by a neurosteroid. The use of 4-MA resulted in not only a reversal of the escapable-shock deficits seen at $24 \mathrm{~h}$ poststress but also an induction of a similar deficit in the inescapable-shock group. It may be that the induction of memory impairment in the inescapable-shock group (4MA condition) may be mediated by neurosteroid derivatives that have been shown to be $\mathrm{GABA}_{\mathrm{A}}$ negative modulators (e.g., pregnenolone sulfate). Further studies will need to be conducted to further elucidate the complex interactions of these neurosteroid derivatives and metabolites. Since we inhibited a metabolic pathway rather than blocking a specific receptor, the evidence implicating the $\mathrm{GABA}_{\mathrm{A}}$ receptor complex, although compelling, is indirect. Due to tonic activity at $\mathrm{GABA}_{\mathrm{A}} / \mathrm{BDZ}$ synapses, the use of antagonists at these synapses would be problematic, because any inhibition of GABA tone would di- 
rectly modulate both learning and memory in this paradigm (McNamara \& Skelton, 1993a, 1993b). The evidence using the 5-alpha reductase inhibitor does, however, demonstrate that the endogenous memory modulator may be a metabolite of either progesterone or deoxycorticosterone.

The present results demonstrate a behavioral ramification of escapable stress: alteration of short- and longterm memory. These findings suggest a novel mechanism, whereby escapable stress may protect against subsequent stress pathology. Alterations in memory of events/contexts associated with the stressor may reduce the proactive interference of the previous stress encounter on subsequent behavioral function of the organism. This may also explain the differences in fear conditioning to environmental cues associated with escapable versus inescapable stress (Desiderato \& Newman, 1971; Mineka et al., 1984). It may be that animals in the escapable-shock group show less fear conditioning because the escapable shock has amnestic consequences that alter the animals' memory for the shock experience. The isolation and characterization of this neurosteroid substance released in the brains of coping subjects may represent a novel pharmacotherapy for stress-related disorders such as anxiety or depression in humans.

\section{REFERENCES}

Anisman, H., Remington, G., \& Sklar, L. S. (1979). Effects of inescapable shock on subsequent escape performance: Catecholaminergic and cholinergic mediation of response initiation and maintenance. Psychopharmacology, 61, 107-124.

Anisman, H., \& SklaR, L. S. (1979). Catecholamine depletion upon re-exposure to stress: Mediation of the escape deficits produced by inescapable shock. Journal of Comparative Physiological Psychology, 93, 610-625.

AnISMAN, H., \& ZaChaRKo, R. M. (1990). Multiple neurochemical and behavioral consequences of stressors: Implications for depression. Pharmacological Therapeutics, 46, 119-136.

Belelli, D., Bolger, M. B., \& Gee, K. W. (1989). Anticonvulsant profile of the progesterone metabolite 5-pregnan-3-ol-20-one. European Journal of Pharmacology, 166, 325-329.

Belelli, D., LAN, N. C., \& GeE, K. W. (1990). Anticonvulsant steroids and the GABA/Benzodiazepine receptor-chloride ionophore complex. Neuroscience \& Biobehavioral Reviews, 14, 315-322.

Bitran, D., Hilvers, R. J., \& Kellogg, C. K. (1991). Anxiolytic effects of 3a-hydroxy-5a[ $\beta]$-pregnan-20-one: Endogenous metabolites of progesterone that are active at the $\mathrm{GABA}_{\mathrm{A}}$ receptor. Brain Research, 561, 157-161.

Bitran, D., Purdy, R. H., \& Kellogg, C. K. (1993). Anxiolytic effect of progesterone is associated with increases in cortical allopregnanolone and $\mathrm{GABA}_{\mathrm{A}}$ receptor function. Pharmacology, Biochemistry \& Behavior, 45, 423-428.

Braestrup, C., Schmiechen, R., Nielsen, M., \& Peterson, E. N. (1982). Benzodiazepine receptor ligands, receptor occupancy, pharmacological effect and GABA receptor coupling. In E. Usdin, P. Skolnick, J. Tallman, D. Greenblatt, \& S. Paul (Eds.), The pharmacology of the benzodiazepines (pp. 71-85). London: Macmillan.

Costa, E., Auta, J., Guidotti, A., Korneyev, A., \& Romeo, E. (1994). The pharmacology of neurosteroidogenesis. Journal of Steroid Biochemistry \& Molecular Biology, 49 (4-6), 385-389.

Crawley, J. N., Glowa, J. R., Majewska, M. D., \& Paul, S. M. (1986). Anxiolytic activity of an endogenous adrenal steroid. Brain Research, 398, 382-385.

Desiderato, O., \& Newman, A. (1971). Conditioned suppression produced in rats by tones paired with escapable and inescapable shock. Journal of Comparative Physiological Psychology, 77, 427-431.
Drugan, R. C., Ader, D. N., \& Maler, S. F. (1985). Shock controllability and the nature of stress-induced analgesia. Behavioral Neuroscience, 99, 791-801.

Drugan, R. C., Basile, A. S., Ha, J. H., \& Ferland, R. J. (1994). The protective effects of stress control may be mediated by increased brain levels of benzodiazepine receptor agonists. Brain Research, 661, 127-136.

Drugan, R. C., McIntyre, T. D., Alpern, H. P., \& Maier, S. F. (1985). Coping and seizure susceptibility: Control over shock protects against bicuculline-induced seizures. Brain Research, 342, 9-17.

Drugan, R. C., Paul, S. M., \& Crawley, J. N. (1993). Decreased forebrain $\left[{ }^{35} \mathrm{~S}\right]$ TBPS binding and increased $\left[{ }^{3} \mathrm{H}\right]$ muscimol binding in rats that do not develop stress-induced behavioral depression. Brain Research, 631, 270-276.

Drugan, R. C., Ryan, S. M., Minor, T. R., \& Maier, S. F. (1984). Librium prevents the analgesia and shuttlebox escape deficit typically observed following inescapable shock. Pharmacology, Biochemistry \& Behavior, 21, 749-754.

DunN, A. J. (1988). Changes in plasma and brain tryptophan and brain serotonin and 5-hydroxyindoleacetic acid after footshock stress. Life Science, 42, 1847-1853.

Fadda, F., Argiolas, A., Melis, M. R., Tissari, A. H., Onali, P. L., \& Gessa, G. L. (1978). Stress-induced increase in 3,4-dihydroxyphenylacetic acid (DOPAC) levels in the cerebral cortex and nucleus accumbens: Reversal by diazepam. Life Science, 23, 22192224.

Fekete, M. I., Szentendrei, T., Kanyicska, B., \& Palkovits, M. (1981). Effects of anxiolytic drugs on the catecholamine and DOPAC (3,4-dihydroxyphenylacetic acid) levels in brain cortical areas and on corticosterone and prolactin secretion in rats subjected to stress. Psychoneuroendocrinology, 6, 113-120.

File, S. E., \& PeARCE, J. B. (1981). Benzodiazepines reduce gastric ulcers induced in rats by stress. British Journal of Pharmacology, 74, 593-599.

FILE, S., \& Pellow, S. (1988). Low and high doses of benzodiazepine inverse agonists respectively improve and impair performance in passive avoidance but do not effect habituation. Behavioural Brain Research, 30, 31-36.

FoY, M. R., FoY, J. G., Levine, S., \& Thompson, R. F. (1990). Manipulation of pituitary-adrenal activity affects neural plasticity in the hippocampus. Psychological Science, 1, 201-204.

Foy, M. R., Stanton, M. E., Levine, S., \& Thompson, R. F. (1987). Behavioral stress impairs long-term potentiation in rodent hippocampus. Behavioral \& Neural Biology, 48, 138-149.

Gee, K. W., Bolger, M. B., Brinton, R. E., Coirini, H., \& McEwen, B. S. (1988). Steroid modulation of the chloride ionophore in rat brain: Structure-activity requirements, regional dependents and mechanism of action. Journal of Pharmacology \& Experimental Therapeutics, 246, 803-812.

Harrison, N. L., Majewska, M. D., Harrington, J. W., \& Barker, J. L. (1987). Structure-activity relationships for steroid interaction with the $\gamma$-aminobutyric acid ${ }_{\mathrm{A}}$ receptor complex. Journal of Pharmacology \& Experimental Therapeutics, 241, 346-353.

Hinrichs, J. V., GHONeIM, M. M., \& MeWALdT, S. P. (1984). Diazepam and memory: Retrograde facilitation produced by interference reduction. Psychopharmacology, 84, 158-162.

IrWin, M., Hauger, R. L., \& BritTon, K. (1993). Benzodiazepines antagonize central corticotropin releasing hormone-induced suppression of natural killer cell activity. Brain Research, 631, 114 118.

IzQUIERDO, I., \& MEDINA, J. H. (1991). GABA A receptor modulation of memory: The role of endogenous benzodiazepines. Trends in Pharmacological Science, 12, 260-265.

JACKSON, R. L., MAIER, S. F., \& CoON, D. J. (1979, October 5). Longterm analgesic effects of inescapable shock and learned helplessness. Science, 206, 91-94.

KATZ, R. J., \& LiebleR, L. (1978). GABA involvement in memory consolidation: Evidence from posttrial amino-oxyacetic acid. $P s y-$ chopharmacology, 56, 191-193.

KaValiers, M., \& Wiebe, J. P. (1987). Analgesic effects of the progesterone metabolite, 3-hydroxy-5-pregnan-20-one, and possible modes of action in mice. Brain Research, 415, 393-398. 
Kokate, T. G., Svensson, B. E., \& Rogawski, M. A. (1994). Anticonvulsant activity of neurosteroids: Correlation with $\gamma$-aminobutyric acid-evoked chloride current potentiation. Journal of Pharmacology \& Experimental Therapeutics, 270, 1223-1229.

Kusnecov, A. W., \& RaBin, B. S. (1993). Inescapable footshock exposure differentially alters antigen- and mitogen-stimulated spleen cell proliferation in rats. Journal of Neuroimmunology, 44, 33-42.

Laudenslager, M. L., Ryan, S. M., Drugan, R. C., Hyson, R. L., \& MaIER, S. F. (1983, August 5). Coping and immunosuppression: Inescapable but not escapable shock suppresses lymphocyte proliferation. Science, 221, 568-571.

Lawrence, L. J., Gee, K. W., \& Yamamura, H. I. (1984). Benzodiazepine anticonvulsant action: Gamma amino butyric acid-dependent modulation of the chloride ionophore. Biochemistry \& Biophysics Research Communication, 123, 1130-1137.

Lefur, G., Guillox, F., Mitrani, N., Mizoule, J., \& Uzan, A. (1979). Relationships between plasma corticosterone and benzodiazepines in stress. Journal of Pharmacology \& Experimental Therapeutics, 211, 305-308.

LISTER, R. G. (1985). The amnesic action of benzodiazepines in man. Neuroscience \& Biobehavioral Reviews, 9, 87-94.

LUCKI, I., Rickels, K., Giesecke, A., \& Geller, A. (1987). Differential effects of the anxiolytic drugs, diazepam and buspirone, on memory function. British Journal of Clinical Pharmacology, 23, 207-211.

MaIer, S. F., Drugan, R. C., \& GraU, J. W. (1982). Controllability, coping behavior and stress-induced analgesia in the rat. Pain, 12, 47-56.

Maier, S. F., \& Seligman, M. E. P. (1976). Learned helplessness: Theory and evidence. Journal of Experimental Psychology: General, 105, 3-46.

MAJEWSKA, M. D. (1992). Neurosteroids: Endogenous bimodal modualtors of the GABA receptor. Mechanisms of action and physiological significance. Progress in Neurobiology, 38, 379-395.

MCNAMARA, R. K., \& SKELTON, R. W. (1992). Assessment of a cholinergic contribution to chlordiazepoxide-induced deficits of place learning in the Morris water maze. Pharmacology, Biochemistry \& Behavior, 41, 529-538.

McNamara, R. K., \& Skelton, R. W. (1993a). Benzodiazepine receptor antagonists flumazenil and CGS 8216 and inverse-agonist $\beta$. CCM enhance spatial learning in the rat: Dissociation from anxiogenic actions. Psychobiology, 21, 101-108.

MCNAMARA, R. K., \& SKELTON, R. W. (1993b). Effects of intracranial infusions of chlordiazepoxide on spatial learning in the Morris water maze: II. Neuropharmacological specificity. Behavioural Brain Research, 59, 193-204.

MCNaughton, N., \& MoRris, R. G. M. (1987). Chlordiazepoxide, an anxiolytic benzodiazepine, impairs place navigation in rats. Behavioural Brain Research, 24, 39-46.

MineKa, S., CoOK, M., \& Miller, S. (1984). Fear conditioned with escapable and inescapable shock: The effects of a feedback stimulus. Journal of Experimental Psychology: Animal Behavior Processes, 10, 307-323.

MorRis, R. G. M. (1981). Spatial localization does not require the presence of local cues. Learning \& Motivation, 12, 239-260.

Morrow, A. L., Pace, J. R., Purdy, R. H., \& Paul, S. M. (1989). Characterization of steroid interactions with $\gamma$-aminobutyric acid receptorgated chloride ion channels: Evidence for multiple steroid recognition sites. Molecular Pharmacology, 37, 263-270.

PaUl, S. M., \& PURdy, R. H. (1992). Neuroactive steroids. FASEB Journal, 6, 2311-2322.

Paul, S. M., Syapin, P. J., Paugh, B. A., Moncada, V., \& Skolnick, P. (1982). Correlation between benzodiazepine receptor occupancy and anticonvulsant effects of diazepam. Nature, 281, 688-689.
Petty, F., Kramer, G., \& Wilson, L. (1992). Prevention of learned helplessness: In vivo correlation with cortical serotonin. Pharmacology, Biochemistry \& Behavior, 43, 361-367.

Petty, F., \& Sherman, A. D. (1981). GABAergic modulation of learned helplessness. Pharmacology, Biochemistry \& Behavior, 15, 453-457.

Purdy, R. H., Morrow, A. L., Blinn, J. R., \& Paul, S. M. (1990). Synthesis, metabolism, and pharmacological activity of 3-hydroxy steroids which potentiate GABA-receptor-mediated chloride ion uptake in rat cerebral cortical synaptoneurosomes. Journal of Medicinal Chemistry, 33, 1572-1581.

Purdy, R. H., Morrow, A. L., Moore, P. H., \& Paul, S. M. (1991). Stress-induced elevations of $\gamma$-aminobutyric acid type A receptoractive steroids in the rat brain. Proceedings of the National Academy of Science, 88, 4553-4557.

Seiber, W. J., Rodin, J., Larson, L., Ortega, S., Cummings, N., Levy, S., Whiteside, T., \& Herberman, R. (1992). Modulation of human natural killer cell activity by exposure to uncontrollable stress. Brain Behavior \& Immunology, 6, 141-156.

Seligman, M. E. P., \& MaIER, S. F. (1967). Failure to escape traumatic shock. Journal of Experimental Psychology, 74, 1-9.

Sherman, A. D., Allers, G. L., Petty, F., \& Henn, F. A. (1979). A neuropharmacologically-relevant animal model of depression. Neumpharmacology, 18, 891-893.

Sherman, A. D., \& PetTy, F. (1982). Additivity of neurochemical changes in learned helplessness and imipramine. Behavioral Neurology \& Biology, 35, 344-353.

ShORT, K. R., \& MAIER, S. F. (1993). Stress controllability, social interaction and benzodiazepine systems. Pharmacology, Biochemistry \& Behavior, 45, 827-835.

THIEBOT, M. (1985). Some evidence for amnestic-like effects of benzodiazepines in animals. Neuroscience \& Biobehavioral Reviews, 9, 95-100.

Toomey, R. E., Goode, R. L., Petrow, V., \& Neubauer, B. L. (1991). In vivo assay for conversion of testosterone to dihydrotestosterone by rat prostatic steroid 5a-reductase and comparison of two inhibitors. The Prostate, 19, 63-72.

Tsuda, A., \& TANAKa, M. (1985). Differential changes in noradrenaline turnover in specific regions of rat brain produced by controllable and uncontrollable shocks. Behavioral Neuroscience, 99, 802817.

Venault, P., Chapouthier, G., Prado de Carvalho, L., Simiand, J., Morre, M., DodD, R. H., \& Rossier, J. (1986). Benzodiazepine impairs and beta-carboline enhances performance in learning and memory tasks. Nature, 321, 864-866.

Warren, D. A., Castro, C. A., Rudy, J. W., \& Maier, S. F. (1991). No spatial learning impairment following exposure to inescapable shock. Psychobiology, 19, 127-134.

WeIss, J. M. (1971). Effects of punishing the coping response (conflict) on stress pathology in rats. Journal of Comparative Physiological Psychology, 77, 14-21.

Weiss, J. M., Stone, E. A., \& Harrell, N. (1970). Coping behavior and brain norepinephrine levels in rats. Journal of Comparative Physiological Psychology, 72, 153-160.

Weiss, J. M., SUNDAR, S. K., \& BeCKER, K. J. (1989). Stress-induced immunosuppression and immunoenhancement: Cellular immune changes and mechanisms. In E. J. Goetz \& N. H. Spector (Eds.), Neuroimmune networks: Physiology and diseases (pp. 193-206). New York: Alan R. Liss.

(Manuscript received July 5, 1995 revision accepted for publication February 17, 1996.) 